\title{
Changes in the enzyme histochemistry of skeletal muscle during experimental denervation and reinnervation ${ }^{1}$
}

\author{
BARBARA SMITH \\ From the Department of Pathology, St. Bartholomew's Hospital, London
}

It has been suggested (Engel, 1962) that enzyme histochemistry may be useful in the diagnosis of difficult muscle biopsies. There appears to be little difference in the general histochemical picture in skeletal muscle, between man and other mammals, and changes which occur in experimental muscle disease can be used as a pattern against which to examine human biopsy material. This has been done for muscle necrosis and regeneration (Smith, 1965), and in this paper it is proposed to consider the changes occurring in the tibialis anterior muscle of the rat following crush or section of the sciatic nerve.

\section{MATERIALS AND METHODS}

Forty Sprague-Dawley rats, weighing between 100 and 200 g., were used. In 15 the left sciatic nerve was crushed in artery forceps, and in 25 it was divided and about 0.5 $\mathrm{cm}$. removed to delay regeneration. At intervals varying between 48 hours and nine months the animals were killed with chloroform and both right and left tibialis anterior muscles removed, the former serving as a control. A small piece of each muscle was placed on a thin layer of cork and plunged into a mixture of dry ice and acetone. The cork was then attached to a chuck so that $10 \mu$ sections could be cut in a cryostat.

The histochemical methods used included those for the mitochondrial enzymes diphosphopyridine (D.P.N.) and triphosphopyridine (T.P.N.), diaphorase (Nachlas, Walker, and Seligman, 1958), succinate dehydrogenase (Nachlas, Tsou, de Souza, Cheng, and Seligman, 1957) and beta hydroxybutyrate dehydrogenase (Pearse, 1960), and those for the glycolytic enzymes, the D.P.N.dependent $\alpha$ glycerosphosphate and lactate dehydrogenase (Pearse, 1960). Nitro Blue Tetrazolium was used as the tetrazolium salt and phenazine methosulphate (Conklin, Dewey, and Kahn 1962) as the intermediate acceptor for the dehydrogenases. The technique of Takeuchi and Kuriaki (1955) was used for the phosphorylase studies, and that of Holt and Withers (1952) for non-specific esterases. Non-specific acid and alkaline phosphatases were estimated on sections which had been ${ }^{1}$ This work was assisted by a grant from the Muscular Dystrophy Group of Great Britain. fixed at $4 \mathrm{C}$. in formol saline for 15 minutes, using a Gomori technique (Holt, 1959; Gomori, 1939).

\section{RESULTS}

In animals in which the sciatic nerve had been sectioned there was little change visible on the haematoxylin- and eosin-stained preparations for about three weeks. The first change was a rounding of the fibres together with some nuclear proliferation. A week or so later a variation in fibre size was noted, some fibres being swollen and others shrunken. Later still a general atrophy occurred and about three months after section all the fibres were small, except in cases where reinnervation was already beginning. No steps were taken to prevent this. In animals in which the sciatic nerve was crushed changes were never very obvious, although sometimes bundles of small fibres could be seen.

When the normal tibialis anterior of the rat is incubated for mitochondrial enzymes a 'checkerboard' pattern is seen. The dark fibres have a large

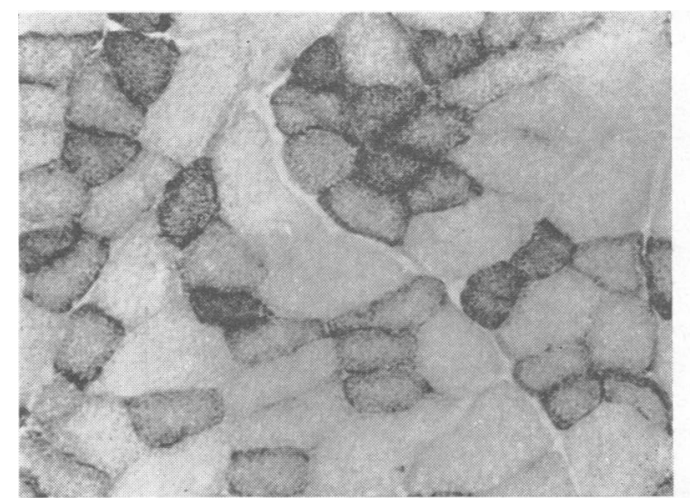

FIG. 1. A succinate dehydrogenase preparation of the normal tibialis anterior of the rat. The 'red' fibres are small and dark, the 'white' fibres are pale and large, and there are a number of intermediate fibres. $\times 85$. 
number of mitochondria and are 'red', and the light have little oxidative activity and are 'white' (Fig. 1). The phosphorylase preparations show a reciprocal pattern.

When the muscle was denervated experimentally little change could be detected histochemically for about five to seven days. The first change was a decrease and eventually a loss of phosphorylase activity. This occurred in a rather patchy fashion, some groups losing their activity much more quickly than others (Fig. 2). Occasional positive fibres were present even when denervation was apparently

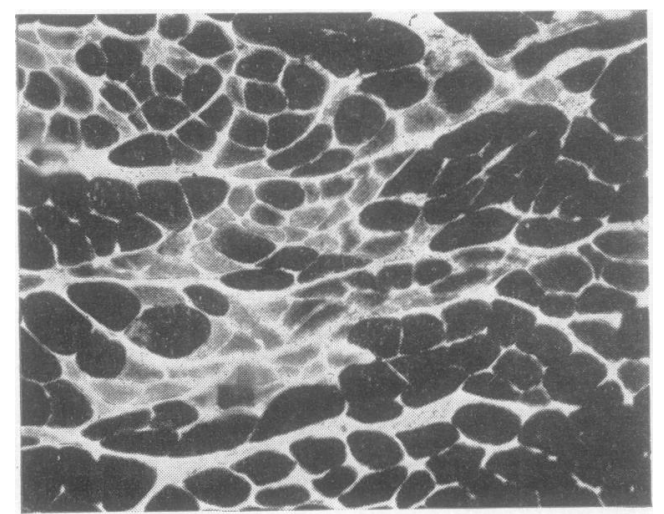

FIG. 2 . complete. The two glycolytic dehydrogenases lost their activity at the same time. Shortly afterwards the checkerboard pattern given by the mitochondrial enzymes began to disappear (Fig. 3). In the case of succinate dehydrogenase and T.P.N. diaphorase this was due to loss of activity in the 'red' fibres producing a uniform coloration. In the case of D.P.N. diaphorase the change was due to an increase in activity of the 'white' fibres, which appeared to contain more mitochondria, the 'red' fibres remaining unchanged. After about three weeks the succinate dehydrogenase and T.P.N. diaphorase preparations

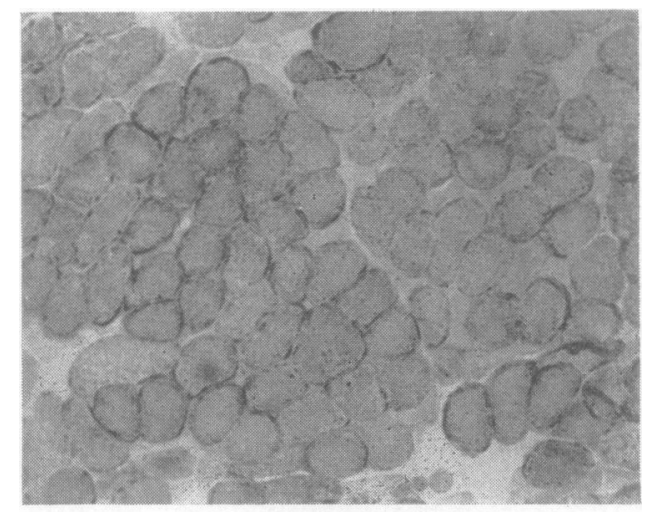

FIG. 3

FIG. 2. A phosphorylase preparation of the tibialis anterior of a rat which had sustained a sciatic nerve cru禹 four weeks previously. The denervation is incomplete but the small fibres contain no enzyme. $\times 75$.

FIG. 3. A succinate dehydrogenase preparation of the tibialis anterior of a rat which had sustained a sciatic nerve section three weeks previously. The fibres are rounded, slightly shrunken, and of uniform colour. Compare with Figure $1 . \times 85$.

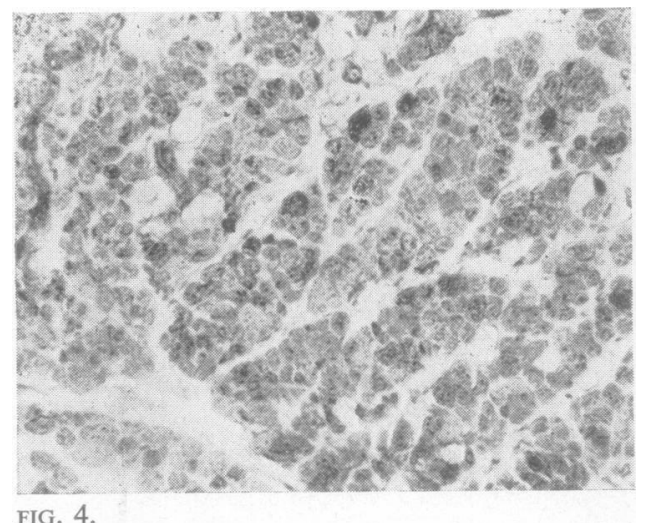

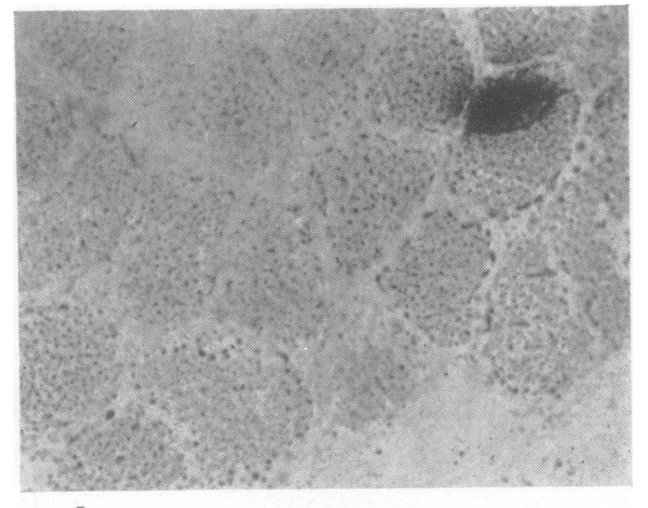

FIG. 5 .

FIG. 4. D.P.N. diaphorase preparation of the tibialis anterior of a rat which had been completely denervated by $\mathbb{N}^{2}$ sciatic nerve section five months previously. The majority of most of the fibres are dark, but a few particularly so. $\times 85.0$ FIG. 5. A non-specific esterase preparation of the tiabilis anterior of a rat which had sustained sciatic nerve section $\mathrm{N}$ eight months previously. All the fibres are active; the dark structure is a motor end-plate which retains its activity but ${ }^{\omega}$ has lost its morphology. $\times 300$. 


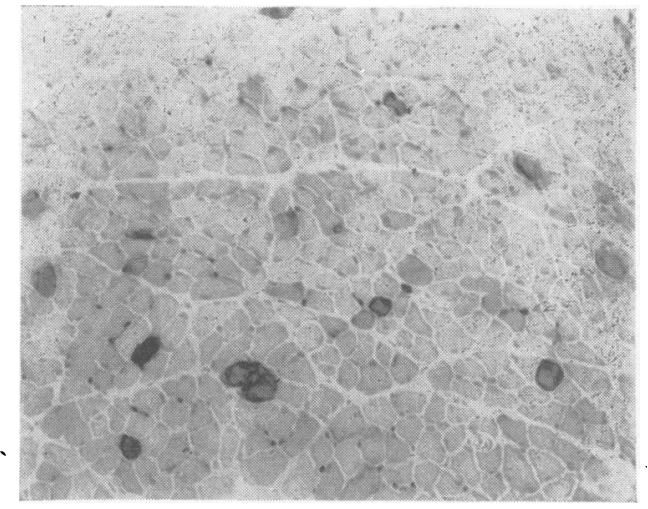

FIG. 6. An alkaline phosphate preparation of the tibialis of a rat which had sustained sciatic nerve section five months previously. Some of the muscle fibres are positive. $\times 115$.

became extremely pale. The D.P.N. diaphorase remained high even when the fibres had completely atrophied (Fig. 4). The beta hydroxybutyrate dehydrogenase and non-specific esterase are normally seen only in 'red' fibres and are very pale. As denervation proceeded all the fibres became 'red' with similar numbers of mitochondria and there was some increase in the activity of these enzymes, particularly the latter (Fig. 5). The motor end-plates are normally well outlined in non-specific esterase preparations and they remained so for the period of these experiments, although the edges became a little uneven. Presumably reinnervation occurs before they are affected.

At the time when the fibres were very small, a few isolated fibres became very dark in both succinate and D.P.N. diaphorase preparations. On sections examined for alkaline phosphatase these same fibres were also noted to be strongly positive (Fig. 6). There was also marked activity of this enzyme in the spindle capsules and the neurilemma (Fig. 7a and b). Normally the only alkaline phosphatase activity present in skeletal muscle is in the blood vessels and in the neurokeratin of myelinated nerve fibres; there is none in muscle fibres. The acid phosphatase preparations showed no abnormality and there was no increase in T.P.N. diaphorase.

As reinnervation occurred the histochemical activity returned and a checkerboard pattern was again apparent. However, in some cases the pattern was not perfect, some bundles remaining phosphorylase negative (Fig. 8), and in bundles in which the phosphorylase activity returned there were sometimes more 'red' fibres than in normal muscle.

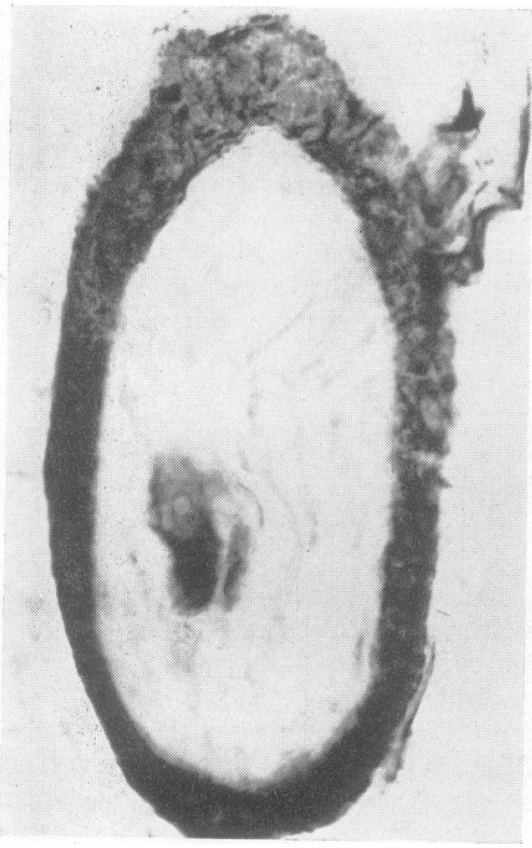

FIG. 7a.

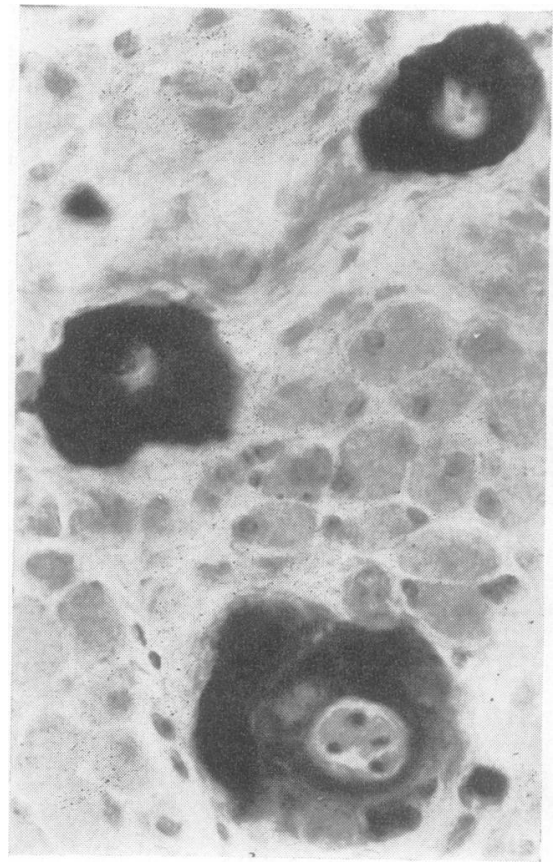

Fig. $7 b$.
FIG. 7a. An alkaline phosphatase preparation of an intramuscular nerve in the tibialis anterior of a rat which had sustained sciatic section eight months previously. There is intense activity in the neurilemma; the dark structure in the centre is a capillary. $\times 250$.

Fig. 7b. From the same section as Fig. $7 a$ to show activity in the spindle capsules. $\times 350$. 


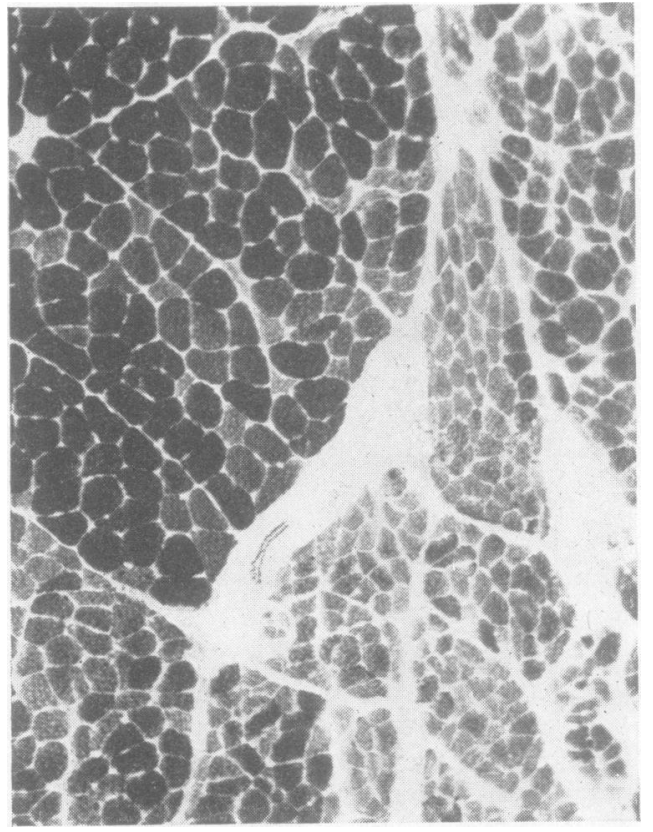

Fig. 8. A phosphorylase preparation of the tibialis anterior of a rat which had sustained sciatic nerve section four months previously. Reinnervation is occurring and enzyme activity is recovering. $\times 75$.

\section{DISCUSSION}

The fact that skeletal muscle has two separate energyproducing systems, each with its own predominant set of enzymes, hampers biochemical studies as all the changes will be diluted. A decrease in succinate dehydrogenase after neurotomy has been noted by Humoller, Griswold, and McIntyre (1951) and Hearn (1959). Varga, Kostya, Szabó, Aszódi, and Kesztyüs (1950) and Schapira and Dreyfus (1959) reported a decrease in glycogenolysis after nerve section, but these findings were contradicted by Matsui and Kuriaki (1959). Nachmias and Padykula (1958) noted decreased succinate dehydrogenase in denervated muscle examined histochemically, with some loss of the distinction between 'red' and 'white' fibres.

The changes demonstrated in this paper are a loss of glycogenolytic activity in all fibres, commencing at about the end of the first week after denervation and progressing to completion in the absence of reinnervation. It is probable that the few phosphorylase-positive fibres remaining when the muscle is atrophied are in fact reinnervated, but have not yet started to increase in bulk. The gradual loss of succinate dehydrogenase activity means that the Krebs cycle is not being used significantly as a source of energy. This is mainly due to the fact that the energy requirements of denervated muscle are only a fraction of those of normally contracting muscle. However the overall increase of D.P.N. diaphorase suggests that possibly some other metabolic pathway is being used.

Skeletal muscle fibres are able to use ketones as a source of energy; in fact this is the physiological method of removing the substances from the blood stream. They can also metabolize fatty acids (Wertheimer and Ben-Tor, 1952) although they normally do not do so as much as cardiac muscle (Slater, 1960). The content of beta hydroxybutyrate dehydrogenase in denervated muscle, always scanty, does not appear to be reduced as much as other mitochondrial enzymes with the exception of D.P.N. diaphorase. Non-specific esterase is increased, even in the 'red' fibres in which it is normally present and much more in the 'white' fibres. This enzyme will hydrolyze or synthesize the esters of carboxylic acids. The exact substrate is not known in this $\infty$ instance, but the enzyme is found where lipids and $i$ fatty acids are being metabolized. The histochemicat 8 appearances of denervated muscle are similar tof 응 cardiac muscle, which contains large quantities of both these enzymes, differing from normal skeleta $>$ muscle. This would suggest that the metabolism of denervated muscle is also similar to cardiac muscle using ketones and fatty acid as a source of energa. Thus it does not need the Krebs cycle for its limite requirements.

The alkaline phosphatase activity in the spindle capsules and in the neurilemma is probably related

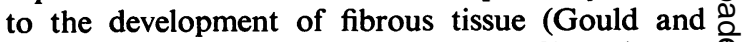
Gold, 1951). Its presence in muscle fibres is not $\stackrel{\mathbb{Q}}{\square}$ understood but the presence of oxidative enzymes in $\overrightarrow{\vec{B}}$ the same fibres suggests that some active process is $\frac{9}{3}$ going on.

The lack of increase in T.P.N. diaphorase activity and the continued absence of acid phosphatase is in contrast to the findings in other types of muscle damage (Smith, 1965). This merely confirms that muscle necrosis and regeneration does not occur 3 . following denervation.

As reinnervation occurs, the phosphorylase and succinate dehydrogenase activity returns and a some- 0 what imperfect checkerboard appearance is again $?$ seen. The larger numbers of 'red' fibres suggest that $\frac{D}{0}$ occasional fibres have failed to recover their glycolytic activity. Often a whole muscle bundle fails to $N$ recover. It has not been possible to establish any $N$ relationship between nerve supply and histo- $N$ chemical type but from comparison of patterns it $\omega$ seems unlikely that one anterior horn cell supplies? 
muscle fibres with only one type of enzyme activity. It is impossible to say whether the 'white' fibres in the reinnervated muscle were 'white' in the original normal muscle, or whether the acquisition of glycolytic activity is a random process.

\section{SUMMARY}

The histochemical changes occurring in denervated muscle fibres are a loss of glycolytic activity and an increase in the number of mitochondria in 'white' fibres, so that the checkerboard pattern is diminished. The mitochondria, although increased in number, show very little Krebs cycle activity, but a normal or increased content of non-specific esterase and beta hydroxybutyrate dehydrogenase activity

It is suggested that the diminished energy requirements of denervated muscle may be obtained from the metabolism of ketones and fatty acids. These changes are reversed when effective reinnervation occurs.

I am grateful to Mr. Peter Crocker for the photographs.

\section{REFERENCES}

Conklin, J. L., Dewey, M. M., and Kahn, R. H. (1962). Cytochemical localization of certain oxidative enzymes. Amer. J. Anat., $11 \theta, 19-26$.

Engel, W. K. (1962). The essentiality of histo- and cytochemical studies of skeletal muscle in the investigation of neuromuscular disease. Neurology (Minneap.), 12, 778-792.

Gould, B. S., and Gold, N. I. (1951). Studies on the 'alkaline' phosphatase associated with regenerating connective tissue fibers. Arch. Path., 52, 413-422.
Gomori, G. (1939). Microtechnical demonstration of phosphatase in tissue sections. Proc. Soc. exp. Biol. (N.Y.), 42, 23-26.

Hearn, G. R. (1959). Succinate-cytochrome c reductase, cytochrome oxidase and aldolase activities of denervated rat skeletal muscle. Amer. J. Physiol., 196, 465-466.

Holt, S. J. (1959). Factors governing the validity of staining methods for enzymes, and their bearing upon the Gomori acid phosphatase technique. Exp. Cell Res., suppl. 7, pp. 1-27.

- - and Withers, R. F. J. (1952). Histochemical localization of esterases using indoxyl derivatives. Nature (Lond.), 170, 1012-1014.

Humoller, F. L., Griswold, B., and McIntyre, A. R. (1951). Effect of neurotomy on succinic dehydrogenase activity of muscle. Amer. J. Physiol., 164, 742-747.

Matsui, T., and Kuriaki, K. (1959). Effect of denervation and cocainization on activity of creatine synthesizing enzyme and phosphorylase in skeletal muscle. Ibid., 196, 461-464.

Nachlas, M. M., Tsou, K. C., de Souza, E., Cheng, C. S., and Seligman, A. M. (1957). Cytochemical demonstration of succinic dehydrogenase by the use of a new p-nitrophenyl substituted ditetrazole. J. Histochem. Cytochem., 5, 420-436.

-, Walker, D. G., and Seligman, A. M. (1958). A histochemical method for the demonstration of diphosphopyridine nucleotide diaphorase. J. biophys. biochem. Cytol., 4, 29-38.

Nachmias, V. T., and Padykula, H. A. (1958). A histochemical study of normal and denervated red and white muscles of the rat. Ibid., 4, 47-54.

Pearse, A. G. E. (1960). Histochemistry, Theoretical and Applied, 2nd ed. Churchill, London.

Schapira, G., and Dreyfus, J. C. (1959). Biochemical changes in muscle consequent upon interruption of the motor nerves. Amer. J. phys. Med., 38, 207-215.

Slater, E. C. (1960). Biochemistry of sarcosomes. In The Structure and Function of Muscle, vol. 2, edited by G. H. Bourne, pp. 105-140. Academic Press, New York.

Smith, B. (1965). Histochemical changes in muscle necrosis and regeneration. J. Path. Bact., 89, 139-143.

Takeuchi, T., and Kuriaki, H. (1955). Histochemical detection of phosphorylase in animal tissues. J. Histochem. Cytochem., 3, 153-160.

Varga, E., Kostya, K., Szabó, E., Aszódi, L., and Kesztyüs, L. (1950). Phosphorylierung in denervieten muskel. Naunyn-Schmiedeberg's Arch. exp. Path. Pharmak., 210, 214-218.

Wertheimer, E., and Ben-Tor, V. (1952). Fat utilization by muscle. Biochem. J., 50, 573-576. 